\title{
Review on Assessment of Anxiety Symptoms of Individuals With Autism Spectrum Disorder
}

\author{
Christine K. Syriopoulou-Delli ${ }^{1}$, Stavroula A. Polychronopoulou ${ }^{2}$, \\ Gerasimos A. Kolaitis ${ }^{3} \&$ Alexandros-Stamatios G. Antoniou ${ }^{4}$ \\ ${ }^{1}$ Department of Educational and Social Policy, University of Macedonia, Greece \\ ${ }^{2}$ Department of Primary Education, National and Kapodistrian University of Athens, Greece \\ ${ }^{3}$ Department of Child Psychiatry, School of Medicine, National and Kapodistrian University of Athens, "Aghia \\ Sophia" Children's Hospital, Greece \\ ${ }^{4}$ Department of Primary Education, National and Kapodistrian University of Athens, Greece \\ Correspondence: Christine K. Syriopoulou Delli, Postdoc, Assistant Professor, Autism Spectrum Disorders, \\ Department of Educational and Social Policy, University of Macedonia, Thessaloniki, 156 Egnatia str., 54336 \\ Thessaloniki, Greece. Tel: 30-693-870-4339. E-mail: csyriop@gmail.com
}

Received: July 29, 2019 Accepted: August 19, 2019 Online Published: September 6, 2019

doi:10.5539/jedp.v9n2p84 URL: http://doi.org/10.5539/jedp.v9n2p84

\begin{abstract}
Background: Review of the criteria of anxiety and its types and subtypes and the instruments and methods used to assess anxiety in people with ASD.

Method: A literature search was made in PubMed and PsychINFO for clinically relevant articles and book chapters published between the 1980s and 2017. In addition, research papers were found through National Institute of Health (NIH) publications.
\end{abstract}

Results: A total of 80 were reviewer of anxiety in people with ASD, with different sample size which document the role of anxiety in their difficulties in adaptation and integration. The studies applied a combined total of 34 instruments to diagnose and evaluate the anxiety of individuals with ASD, using several sources, including the individuals themselves.

Conclusions: Effective way of assessment is the cross-checking of symptoms using different instruments and several sources of information, including parents, teachers and the individuals themselves.

Keywords: assessment, instruments, criteria, anxiety, autism spectrum disorder

\section{Introduction}

Autism spectrum disorder (ASD) is characterized by weaknesses in social communication accompanied by repetitive patterns of behaviors and interests (APA, 2013). In the Diagnostic and Statistical Manual of Psychiatric Disorders (DSM IV \& 5), the criteria for ASD include symptoms of anxiety and specific patterns of behavior including at least two of the following (APA, 1994, 2000, 2013).

1). Stereotypical or repetitive speech, movements or use of objects (such as idiosyncratic phrases, echoing, simple kinetic stereotypes, repetitive use of objects).

2). Excessive adherence to routines, ritual patterns of verbal and non-verbal behaviors, excessive resistance to changes (such as motor rituals, insistence on the same path or food, repetitive questions, or excessive distress on minor changes).

3). Extremely limited, fixed interests that are abnormal or unusual in intensity or focus (such as a strong attachment to unusual objects, exaggerated or persistent interests).

4). Over- or under-reactivity to sensory intakes or unusual interests in sensory aspects of the environment (such as obvious indifference to pain/heat/cold, exaggerated reaction in special sounds or fabrics, excessive interest in the smell or feel of objects, fascination with lights or shiny objects.

Comorbidity of ASD with anxiety disorders is common. About $40 \%$ of people with ASD are reported to present anxiety symptoms, which are associated with poor individual and family functioning (van Steensel et al., 2011; 
Kim et al., 2000; White et al. 2009; Vasa et al., 2016). There is a lack of consensus on differential diagnosis and anxiety assessment among young people with ASD (Ollendick \& White, 2012). Studies on anxiety in children with ASD have generally used instruments that were developed and standardized for use with children of typical development (TD) and which may not differentiate between autistic and anxiety symptoms or detect the different manifestations of anxiety in individuals with ASD. The ways in which symptoms of anxiety in ASD have been measured and described show wide variation among studies, giving rise to inconsistencies in conclusions about the presence and predominance and their association with mental or verbal ability or the severity of ASD (Glod et al., 2017). Inconsistencies in the measurement, evaluation and differentiation of anxiety and ASD may in part, reflect differences in recruitment and samples and the ways of measuring anxiety (Kerns \& Kendall, 2012; White et al., 2009). There is resulting skepticism about whether anxiety assessment leads to appropriate interventions for achieving educational and social inclusion of people with ASD. Efforts since the 1990s have improved the diagnosis of these disorders, but the overall quality of care provided to patients remains rudimentary (Stein et al., 2004). Recent studies found little change in the prevalence of intellectual disorders since 1990 (Kessler, Demier, Frank et al., 2005; White et al., 2009; Kerms \& Kendall, 2012; deBruin et al., 2007; Wood \& Gadow, 2010). It is of great importance to be able to determine if anxiety problems are part of the ASD or separate from, even though interacting with the ASD, as the required intervention, psychosocial, pharmacological and educational, may differ and the targets of intervention will be accordingly different (White et al., 2009; Wood et al., 2009). Many factors make it difficult to estimate anxiety in children with ASD (Keefer et al., 2017). ASD symptoms overlap with those of anxiety and if the differential diagnosis between disorders is not achieved treatment may not be optimal (Papadatos, 2010; Kleberg et al., 2016). The symptoms of anxiety can be difficult to distinguish from the symptoms of ASD (White et al., 2009; Wood \& Gadow, 2010; Kerns \& Kendall, 2012) and there is overlap, according to the Definition in DSM-5 (Table 1). Avoidance of social contact in ASD may be related to social anxiety and it may be unclear for children with ASD if symptoms occurring during separation from the parents are due to separation anxiety or attachment to routine or both (Grondhuis \& Aman, 2012; Gadow et al., 2005; Hallett et al., 2013b; Leyfer et al., 2006; Storch et al., 2012a). Similarly, repetitive behavior is a defining characteristic for both ASD and obsessive compulsive disorder (OCD) (DSM-5). Difficulties with sleep are common in both ASD and anxiety disorders. Children with ASD may present various phobias and specific fears are observed, related, for example to being called to rise in school and to bathroom routines and medical procedures, more frequently in children with ASD than in those with Down syndrome or of TD (Evans et al., 2005; Attwood, 2005; Polychronopoulou, 2012; Lecavalier er al., 2014; Leyfer et al., 2006; Simonoff et al., 2008).

Table 1. Anxiety disorders in the diagnostic and statistical manual of mental disorders (DSM-5)

Diagnostic and Statistical Manual of Mental Disorders (DSM) (Anxiety and Depression, Association of America).

DSM-5 Disorders

Anxiety Disorders

Separation Anxiety Disorder

Selective Mutism

Specific Phobia

Social Anxiety Disorder (Social Phobia)

Panic Disorder

Panic Attack (Specifier)

Agoraphobia

Generalized Anxiety Disorder

Substance/Medication-Induced Anxiety Disorder

Anxiety Disorder Due to Another Medical Condition

Other Specified Anxiety Disorder

Unspecified Anxiety Disorder 


\title{
Obsessive-Compulsive and Related Disorders
}

Obsessive-Compulsive Disorder

Body Dysmorphic Disorder

Hoarding Disorder

Trichotillomania (Hair-Pulling Disorder)

Excoriation (Skin-Picking) Disorder

Substance/Medication-Induced Obsessive-Compulsive and Related Disorder

Obsessive-Compulsive and Related Disorder Due to Another Medical Condition

Other Specified Obsessive-Compulsive and Related Disorder

Unspecified Obsessive-Compulsive and Related Disorder

\section{Trauma- and Stressor-Related Disorders}

Reactive Attachment Disorder

Disinhibited Social Engagement Disorder

Posttraumatic Stress Disorder

Acute Stress Disorder

Adjustment Disorders

Other Specified Trauma- and Stressor-Related Disorder

Unspecified Trauma- and Stressor-Related Disorder

\author{
Depressive Disorders \\ Disruptive Mood Dysregulation Disorder \\ Major Depressive Disorder, Single and Recurrent Episodes \\ Persistent Depressive Disorder (Dysthymia) \\ Premenstrual Dysphoric Disorder \\ Substance/Medication-Induced Depressive Disorder \\ Depressive Disorder Due to Another Medical Condition \\ Other Specified Depressive Disorder \\ Unspecified Depressive Disorder
}

Somatic Symptom and Related Disorders

Illness Anxiety Disorder

\subsection{Overview of Anxiety Symptoms in ASD}

White and colleagues in a review of 11 studies including 1,353 young people with ASD aged 6-18 years which reported anxiety rates ranging from $11 \%$ to $84 \%$ based on observation, interview and questionnaires (White et al., 209). Only two studies (de Bruin et al., 2007; Simonoff et al., 2008) reported rates for anxiety disorders (55 and $42 \%$, respectively) based on a structured diagnostic interview. MacNeil and colleagues reviewed 13 studies (several of which were also in White's review) in which a weighted measurement of anxiety was performed (MacNeil et al., 2009). Both reviews concluded that findings may vary, depending on the age. And IQ of the subjects, the assessment method (interview, questionnaire), the informants (parents, children) and ASD subtypes. VanSteensel and colleagues (2011) in a meta-analysis of anxiety disorders in young individuals with ASD evaluated factors that affect the observed heterogeneity. Physical symptoms may include rapid heartbeat, headaches stomachache, muscle tension, sweating, irregular movements and behavior, breathing problems (not asthma), nausea, diarrhea, sensory disorders, disruptive behavior and talking to themselves as if they were calming themselves or rationalizing a situation (Meiser-Stedman et al., 2017). Anxiety may provoke repetitive behavior that appear to serve no function, such as walking, shuffling, cutting paper or ripping apart clothing. Anxiety can result in insomnia, difficulty in concentration, negative thinking, refusal to attend school, excessive shame and isolation, fear of failure, lack of help, defensiveness, hypochondria and, if untreatable, suicidal thoughts and actions. Although common among people with ASD, anxiety should not be ignored or left untreated (Wood \& Gadow, 2010). In addition to the basic features of ASD, children and adolescents with ADHD may also present 
concomitant problems such as nervousness, aggression, hyperactivity and anxiety (Lecavalier, 2006; White et al., 2009; Telman et al., 2017; Amaral, Bauman, \& Schumann, 2003; Apter et al., 1991). Bellini (2006) reported that overstimulation combined with weakness in social skills predicts social anxiety in people with ASD. Awareness in high-functioning young people with ASD of their social disability in terms of misinterpreting social clues and expectations of social failure may aggravate their anxiety and exacerbate their social disability (Myles et al., 2001; White \& Roberson-Nay, 2009). Anxiety can thus contribute to social avoidance and reduce opportunities to practice appropriate social skills. Although some individuals with ASD may be protected by lack of insight into their social difficulties, many young people with ASD are "particularly aware of their difficulties in social inclusion" (Attwood, 2005, p.97) and experience more loneliness than children of TD (Bauminger \& Kasari, 2000). As the complexity of social relationships and social demands increase in secondary education children with ASD may become more aware of their social disability (Schopler \& Mesibov, 1994) which can contribute to changing of mood and development of anxiety (Myles et al., 2001; Wood \& Gadow, 2010; Piven \& Palmer, 1999). Adults with ASD show psychiatric comorbidity, including increased anxiety, panic, agoraphobia, OCB and generalized anxiety disorder (GAD) symptoms (Gillot \& Standen, 2007; Rumsey et al., 1985). Higher rates of post-traumatic stress disorder (PTSD) were found in early studies of individuals with developmental disorders and in children with developmental disorders (Kristensen, 2000). Higher rates of sleep disturbance were observed found in preschool children with developmental disorders (DeVincent et al., 2007). Clinical performance rates were found lower in children with developmental disorders than in children with other psychiatric problems, including anxiety disorders (Bastiaansen et al., 2004). It has been suggested that in ASD sensory perception and communication difficulties and limited flexibility may contribute to anxiety (Matson \& Nebel-Schwalm, 2007; van Steensel, Bogels, \& Perrin, 2011; Jensen Mrazek et al., 1997; Mehtar \& Motavalli, 2011; Kerns \& Kendall, 2012; Wood \& Gadow, 2010). An increase in stereotypical and provocative behavior may reflect an attempt to reduce the stimulation of high levels of anxiety (Hallett et al., 2013b; Ozsivadjan et al., 2012). Many different factors appear to affect the anxiety in this population. Much of the information on types of anxiety disorder have been derived from samples of people with ASD without additional mental disability (Kuusikko et al., 2008; Renno \& Wood, 2013; White et al., 2015; MacNeil et al., 2009; VanSteensel et al., 2011) which limits our understanding of the effect of mental or adaptive capacity in more severe ASD. Herrington and colleagues (2016) conducted a literature review of anxiety in ASD, with a particular focus on the relationship between child characteristics and subtypes of anxiety (social, general, OCD etc.).

DSM-5 lists different types of anxiety, including PTSD (Mehtar \& Motavalli, 2011), OCD, panic attacks, social anxiety, GAD, special phobias and substance causing anxiety disorder (Rowney et al., 2010). In a future version of DSM, their development and adaptation of reliable scales may improve the diagnosis of co-morbidity in people with developmental disorders (APA, 2013; Matson \& Nebel-Schwalm, 2007; van Steensel, Bogels, \& Perrin, 2011; Jensen, Mrazek et al., 1997).

As the National Institute of Mental Health points out, mental illnesses are complex and result from a combination of genetic, environmental, psychological and developmental factors (NIMH, 1999b). Stress is a natural reaction and a necessary warning of human adaptation. Adaptation can become a pathological disorder when it is excessive and out of control. It does not necessarily require external stimuli but may be raised by a wide variety of physical and emotional symptoms as well as changes in behavior and cognition. A genetic predisposition has been identified for two major groups of anxiety disorders, panic and agoraphobia (Hettema et al., 2005) and intergenerational effects have been noted in a long-term study (Weissman et al., 2006).

Pathophysiological mechanisms have not been fully elucidated, but the symptoms of anxiety are believed to be due ti impaired configuration in the central nervous system. Possible explanations include structural (Amaral et al., 2003) and neurochemical disorders (Apter et al., 1991) in the brain that predispose individuals with ASD to experience anxiety with a possible genetic link between ASD and anxiety (Piven \& Palmer, 1999). The physical and emotional manifestations are a result of increased stimulation of the sympathetic system and neurotransmitter system are involved in the regulatory steps (Hoehn, McLeod, Funderburk et al., 2004; Bowirrat et al., 2010). The most common pathways are the serotoninergic and the noradrenergic neurotransmitter systems regulated by neural networks in different regions of the brain, including the caeruleus and limbic structures (Herrington et al., 2016). Corticosteroids may increase or decrease the activity of nerve pathways that affect stress-based behavior and brain processes involving fear (Herrington et al., 2016).

Psychophysiological and brain imaging studies confirmed the association of developmental disorders with deregulation of the functioning of the autonomic nervous system, indicated by abnormal cardiovascular, electrodermal responses (Rowney, Hermida, \& Malone, 2010; Hettema et al., 2005; Weissman et al., 2006; Bowirrat et al., 2010; Herrington, Miller, Pandey, \& Schultz, 2016; Hoehn et al., 2004; Palkovitz \& Wiesenfeld, 
1980; James \& Barry, 1984; Stevens \& Gruzelier, 1984; Romanczyk et al., 2006). Romanczyk and colleagues supported the use of psycho-physical recording in the assessment of anxiety in children with ASD. More pronounced autonomic responses were induced by a laboratory stressor in people with high functional ASD than in those of TD and individuals with schizophrenia (Zahn et al., 1987). A review of functional neuropathological studies concluded that positron emission tomography (PET) showed serotonin and dopamine abnormalities. Magnetic resonance imaging (MRI) showed metabolic weaknesses in the frontal cortex and cerebellum, while magnetoencephalography (MEG) showed higher epileptic activity in patients with ASD. Structural and functional abnormalities in the amygdala hippocampus and the limbic system were associated with emotional processes in ASD including fear and anxiety (LaBar et al., 2006; Mitelman et al., 2017).

To date the only feasible method of assessment of anxiety is by application of one or more of the instruments that have been developed for this purpose. The development of intervention strategies for ASD populations based on the availability of reliable measurements that are sensitive to change when interventions are applied. Wigham \& McConachie (2014) reviewed instruments used to improve the response of young people with ASD.

According to one relevant review 36 different methods of assessment have been used to measure anxiety in children with ASD, including instruments for self-administration and others for parents, clinical staff and teachers (LaBar et al., 2006; Mitelman et al., 2017; Gillot, Standen, 2007; Rumsey et al., 1985; DeVincent et al., 2007; Kristensen, 2000; Bastiaansen et al., 2004; Grondhuis \& Aman, 2012). With few exceptions (Gadow et al., 2005; Hallett et al., 2013b; Leyfer et al., 2006; Storch et al., 2012a), most of the instruments used to measure anxiety in children with ASD were developed for use with children of TD. And have been evaluated in this population. In addition, young people with ASD may have difficulty with self-referral tools, especially if they have significant cognitive constraints (Wood \& Gadow, 2010).

This review aimed to provide an update on the instruments and processes of assessment of anxiety symptoms used in studies conducted with people with ASD in order to understand their mental and emotional state better. The ultimate objective was to define the best means of identification and measurement of anxiety in young people with $\mathrm{ASD}$, as a basis for appropriate intervention.

The literature review was guided by the following questions:

i) What are the current trends regarding anxiety criteria and the instruments and methods of assessment of anxiety in young people with ASD?

(ii) How can ASD symptoms be distinguished from anxiety symptoms?

(iii) Do school children with ASD present more symptoms of anxiety disorder then those of TD?

(iv) In which ways is the anxiety of children with ASD expressed at school and out of school?

(v) How are the components of anxiety in children with ASD assessed by the study instruments related to each other?

(vi) How is anxiety and its components parts in children with ASD related to their demographic and epidemiological characteristics?

(vii) Are teachers perception on the anxiety of children with ASD school consistent with those of their parents when the children are not in school?

\section{Methods}

The selection of the studies on anxiety in people with ASD for the purpose of this paper was based on two criteria: i) the study sample consisted of people diagnosed with ASD, ii) the study included the use of a specific instrument or instruments for the assessment of anxiety.

It was intended to include studies carried out in different countries, to provide a range of cultural environmental settings. An electronic search was conducted in PubMed and PsychINFO. Clinically relevant articles not indexed in PubMed or PsychINFO, book chapters and research papers and books were found through National Instituted of Health (NIH) publications and in the library of the University of Macedonia and the Greek National Foundation of Research.

\section{Results}

The literature search yielded 150 studies published between 1980s and 2017 of anxiety in people with ASD which affected their ability to adapt and integrate. In addition, 12 reviews and 7 book chapters were found which included information on instruments for assessing anxiety. Of these 80 fulfilled the criteria of this review. They described a total of instruments used for diagnosing and/or assessing anxiety. 


\subsection{The Instruments}

Table 2 lists the instruments most commonly used for assessment of anxiety in people with ASD in the studies reviewed here.

Table 2. Instruments that have been used for measuring Anxiety in people with ASD

1 Mood and Anxiety Semi-Structured Interview (Charlot et al., 2007)

2 ADIS-CIP (Anxiety Disorder Severity Ratings)

3 Pediatric Anxiety Rating Scale (PARS) (RUPP Anxiety Study Group, 2002; Storch et al., 2012b)

4 Behavior Assessment System for Children- Second Edition (BASC-2) (Reynolds \& Kamphaus, 2000)

5 Negative Affective Self-Statement Questionnaire (NASSQ) (Roman et al., 1994; Grodhuis \& Aman, 2012; Lecavalier et al., 2014)

6 Fear Survey for Children (Ramirez \& Lukenbill, 2007; Matson \& Love, 1990; Li \& Morris, 2007)

7 Anxiety, Depression and Mood Scale (Esbensen et al., 2003)

8 Glasgow Anxiety Scale for people with mental disabilities (Mindham \& Espie, 2003; Dekker et al., 2002)

9 Psychopathology Inventory for Mentally Retarded Adults (Balbo et al., 2000; Masi et al., 2002)

10 Psychiatric Assessment Schedule for Adults with Developmental Disability, the Anxiety Disorders section of the Diagnostic Interview Schedule for Children (Dekker \& Koot, 2003; Muris et al., 1998)

11 Early Child Inventory and Child Symptoms Inventory (Weisbrot et al., 2005; Gadow et al., 2004)

12 Yale-Brown Obsessive Compulsive Scale (McDougle et al, 1995)

13 School Anxiety Scale- Teacher Report (SAS-TR) (Lyneham et al., 2008)

14 The Child Behavior Checklist (CBCL)(Achenbach, 2005; Achenbach \& Rescorla, 1991; 2001; Dutra et al., 2004; Fischbach \& Lord, 2011)

15 Anxiety Scale for Children Autism Spectrum Disorder (ASC-ASD) (Rodgers et al., 2016)

16 Spence Children's Anxiety Scale - Children's Version (SCAS-C)

17 Spence Children's Anxiety Scale- Parents' Version (SCAS-P) (Nauta et al., 2004)

18 Screen for Child Anxiety Related Disorders (SCARED)

19 Screen for Child Anxiety Related Disorders- Parent Version (SCARED-PV) (Magiati et al., 2016)

20 Multidimensional Anxiety Scale for Children 2nd edition (MASC 2) (March, 2000)

21 Revised Children's Manifest Anxiety Scale (Reynolds \& Richmond, 1978)

22 Short Leyton Obsessional Inventory- Child Version (Bamber et al., 2002)

23 Anxiety Disorders Interview Schedule - Child/ Parent

24 Revised Child Anxiety and Depression Scale (RCADS)

25 Child and Adolescent Symptom Inventory, fourth edition (CASI-4R)

26 Ontario Child Health Study

27 Loneliness Questionnaire (Asher et al., 1984)

28 Bauminger Loneliness Scale (Bauminger et al., 2003)

29 CASI-4 anxiety scale

30 Autism Diagnostic Observation Schedule (ADOS) (Lord et al., 2002)

31 Social Communication Questionnaire (SCQ) (Berument et al., 1999; Rutter et al., 1994)

32 Social Response Scale (SRS) (Constantino \& Gruber, 2005)

33 Social Competence Inventory (SCI) (Rydell et al., 1997)

34 Kiddie Schedule for Affective Disorders and Schizophrenia (Mattila et al., 2010) 
Most of the instruments were not designed for use with people with ASD and some were originally intended for adults and adaptations have been proposed for use with young people with ASD (Stavrakaki et al., 2007; Sclauch et al., 2007; Bailey \& Andrews, 2003). Mohr and Costello (2007) reviewed a number of instruments that have been used in various studies for monitoring psychiatric symptoms and psychometric findings in people with intellectual disabilities (deBruin et al., 2007; Mehtar \& Mukaddes, 2011; Wozniak et al., 1997; Gadow et al., 2005; Herguner \& Motavalli, 2009; vanSteensel et al., 2011; Dawson \& Bernier, 2013). The Mood and Anxiety Semi-Structured Interview, based on the criteria of DAS IV-TR, has shown validity and sensitivity in the assessment of patients with intellectual disabilities (Charlot et al., 2008).

The Fear Survey for Children showed good internal consistency and moderate correlations with other measurements of anxiety 138 adults with mental retardation (MR) (Ramirez \& Lukenbill, 2007) and was used to evaluate fear and anxiety in children with (MR) and learning difficulties. Parental assessment version of the Fear Survey for Children showed a greater number of fears in children with developmental disorders (Matson, Love, 1990) and association with age, gender and disability levels.

The Anxiety Depression and Mood Scale tested on 129 patients with clinical MR showed good internal consistency but moderate reliability (Esbensen et al., 2003).

Other instruments tested include the Glasgow Anxiety Scale for people with a mental disability, which showed validity and reliability (Mindham \& Espie, 2003; Dekker et al., 2002), the Psychopathology Inventory for Mentally Retarded Adults (Balboni et al., 2000; Masi et al., 2002), the Psychiatric Assessment Schedule for Adults with Developmental Disability, the Anxiety Disorders section of the Diagnostic Interview Schedule for Children (Dekker \& Koot, 2002; Muris et al., 1999) and the Early Child Inventory and Child Symptoms Inventory based on DSM-IV criteria (Weisbrot, Gadow, Vincent Promeroy et al., 2005) have also been used.

The Yale-Brown Obsessive Compulsive Scale detected obsessive and compulsive behaviors in adults with ASD and OCD with adults with OCD but no developmental disturbances the (McDougle et al., 1995).

Several instruments have been used specifically for assessing anxiety in children and young people with ASD. An adapted version of the Ontario Child Healthy Study questionnaire completed by parents of 59 children with ASD aged between 9 and 12 years revealed general anxiety in $13.6 \%$ and separation anxiety in $8.5 \%$ (Kim et al., 2000).

An adapted version of the Kiddie Schedule for Affective Disorders and Schizophrenia (KSADS) was used to collect information from the carers of 109 children with ASD aged 5-17 years the most common anxiety disorder detected was phobia (44.3\%) followed by OCD (37.2\%) and separation anxiety (11.9\%) (Leyfer et al., 2006).

Simonoff and colleagues (2008) through parental interviews based on DSM-IV diagnostic criteria for anxiety disorder and social anxiety disorder is the most common form (29.2\%), followed by GAD (13.4\%) in a sample of 112 children and young people with ASD aged 10-24 years.

An effort has been made to design instruments for assessing anxiety in children with ASD and those of TD for use with teachers, parents and the children themselves.

The School Anxiety Scale Teacher Report (SAS-TR) evaluates teachers' perceptions of the symptoms of generalized and social anxiety presented by the child in the school setting. The SAS-TR is designed for assessment of children aged 5 to 12 years. The Child Behavior Checklist (CBCL) (Achenbach \& Rescorla, 2001) is a 120-item instrument completed by the parent with a 3 -point scale $(0=$ not true, $1=$ sometimes true and $2=$ always true or often true) designed to measure behavioral and emotional problems and social skills in typical 4-18 year old children. It includes two parts, one to evaluates the child's social capacity and the other emotional and behavioral problems in the past 6 months. Two broad categories (internalization and externalization) can emerge.

The CBCL covers 8 dimensions including aggressive behavior, anxiety/depression, attention problems, behavior violation, social problem, body complaints, thinking problems and withdrawal/depression. The scales have shown internal consistency $(.90)$ reliability and validity and stability on re-check (.89).

It has been used in studies of children with ASD (Fischbach \& Lord, 2010). Kuusikko and colleagues (2008) created a revised version of the CBCL, the Social Anxiety Scale for Children -Revised, and Social Phobia and Anxiety Inventory for Children, blocking items that may overlap with sympotms of ASD. In addition, there is the Anxiety Scale for Children's Autism Spectrum Disorder (ASC-ASD) tool.

The Screen for Child Anxiety Related Disorders (SCARED) is a 41-item instrument completed on a 3-point Likert-type scale. It is published in two versions: one of which, the parent's version (SCARED-PV) puts questions to parents about the child and the other asks the same questions to the child directly (Magiati et al., 2015). The purpose of the tool is to record signs of anxiety disorders in children. Screen for Child Anxiety Related Disorders - 


\section{Parent Version.}

Spence's Children's Anxiety Scale (SCAS-C) evaluates the severity of anxiety symptoms in general with regard to the anxiety disorder proposed by DSM-IV. The scale evaluates six areas of anxiety including general anxiety, panic/agoraphobia, social phobbia, separation anxiety, obsessive compulsive disorder and fear of physical injury. It is designed to be completed by children relatively easily and quickly, taking about 10 minutes to answer the questions. The instrument includes 44 items, ranked on a 4-point scale, of which 38 reflect specific anxiety symptoms and 6 are related to positive aspects, to reduce negative bias in responses SCAS-P is the parental version of SCASS, adapted for completion by the parents of the children (Nauta et al., 2004).

Hierarchical classification by regression analysis provides SCAS-P subscales, including separation anxiety, social phobia, generalized anxiety, panic attack and agoraphobia, physical injury fears and OCD (Magiati et al., 2015).

Multidimensional Anxiety Scale for Children 2 nd Edition ${ }^{\mathrm{TM}}$ is a revised version of the Multidimensional Anxiety Scale for Children (MASC). It is completed by the child in less than 15 minutes and evaluates anxiety related symptoms in young people aged 8 to 19 years. The instrument consists of 39 items which assess four major parameters of anxiety (physical symptoms, injury avoidance, social separation/panic) and produces an index of total anxiety. It shows good reliability (.88) and stability (.93) for over 3 months, and which the exception of injury avoidance, correlates significantly with the Revised Children's Manifest Anxiety Scale (Reynolds \& Richmond, 1978). The tool distinguishes between serious anxiety symptoms and dimensions and other tools usually do not detect and contributes to early detection, diagnosis, treatment planning and monitoring. It is consistent for males and females and younger and older children.

The Behavior Assessment System for Children - 2 (BASC-2) (Reynolds \& Kamphaus, 2004; Bradstreet et al., 2017) has subscales for anxiety as does the Negative Affective Self-Statement Questionnaire (NASSQ) (Roman, et al., 1994; Grodhuis \& Aman, 2012; Lecavalier et al., 2014). A few studies have adapted scales to assess anxiety in young people with ASD (Sukhodolsky et al., 2008), which may be identified with the symptoms of ASD (e.g. difficulty in paying attention). From the Computer-assisted self-interviewing system (CASI-4) anxiety scale a customized 20-item index with moderate internal consistency has been created (Cronbach's alpha $=0.85$ ). There have been no studies to evaluate the agreement between these scales and a diagnostic interview, but they provide a step towards understanding the logic of existing anxiety scales. Revised scores can be an additional way of adapting such tools for young people with AS (Mazefsky et al., 2014; vanSteensel et al., 2011; Kerns et al., 2015).

The Autism Diagnostic Observation Schedule (ADOS) (Lord et al., 2002) is a structured interview-based and observational assessment performed with the child's participation. The child is presented with activities and questions that attract communication and social behaviors typically for people with ASD. Algorithms for communication and socialization are calculated to support the diagnosis of ASD. ADOS typically takes 30-45 minutes to complete and has high reliability (Lord et al., 2002).

The Social Communication Questionnaire (SCQ) (Berument et al., 1998; Tutter et al., 1994) is a successful diagnostic interview for ASD. Completed by the parent or guardian of the child in about 10 minutes, SCQ is a reliable instrument with internal coherence from .84 to .93 (Rutter et al., 2003) for assessing and diagnosing ASD. Although the usual score for the purpose of diagnosis is 15 (Rutter et al., 2003), in higher functioning children a lower limit is acceptable if the diagnosis is supported by clinical evaluation by other means (Corsello et al., 2007).

The Social Response Scale (SRS) (Constantino \& Gruber, 2005), completed by the parent is a 65 -item scale that measures autism symptoms as they occur in typical social situations. It is completed in 15 to 20 minutes and yield a total score reflecting the seerity of social weaknesses in ASD and symptoms in 5 key areas. The inner coherence of the SRS is excellent $(\mathrm{a}=.97)$ (Constantino \& Gruber, 2005). The SRS provides a measurement of ASD, with higher scores in SRS showing a greater degree of social disability.

The Social Competence Inventory (SCI) (Rydell et al., 1997) supplemented by the parent is a 25 -object questionnaire rated on a 5-point Likert scale. It contains two sub-scales derived from the factor analysis: The Index of Prosocial Orientation (PO) (17 items), which assesses the child's ability to behave appropriately in normal and problematic (e.g. conflict) social conditions with adults and the Social Initiative Index (SI) (8 items), which measures he child's ability to take social initiatives with peers. Higher scores show better social function. Both scales have been validated with regard to behavioral observations and have excellent reliability $(a=.88$ and .75$)$.

The Loneliness Questionnaire (Asher et al., 1985) is a weighted self-referencing tool that evaluates the feelings of loneliness.

Bauminger \& Kasari (2000) have developed a scale of 24 items with internal coherence (.93) to evaluate loneliness in children with ASD. In addition, in an index of "spherical" loneliness, the scale distinguishes between emotional 
loneliness or feelings of loneliness and lack of tender bonds ( 9 questions) and social loneliness or the child's perception of lack of social intercourse with peers (13 questions) (White et al., 2009).

The Kiddie Schedule for Affective Disorders and Schizophrenia (Mattila et al., 2010) has also been used with children with ASD.

\subsection{The Studies}

Several studies have attempted to compare the effectiveness of different methods of measurement of anxiety. One study focused on the accuracy of brief anxiety scales for young people with ASD. The extended version of the Anxiety Disorders Interview Schedule - Child/Parent, designed to detect formal and informal from PARS and BASC-2 and SCARED were completed by 54 children with ASD (age range 7-17 years, IQ: 67-158) and their parents. The results showed that the scoring was not sensitive and the detection of non-formal fears was particular poor. The authors concluded that revised tools are needed to research young people with ASD (Nauta et al., 2004; Magiati et al., 2015).

Non-typical anxiety symptoms detected included unusual specific phobia (such as fear of fans, advertising songs, bubbles), excessive anxiety about change, oppressive, coercive behavior that could not be directly linked to unwanted thoughts or feelings, and social fear despite the limited awareness of social criticism. Other studies have described, but have not formally assessed such non-formal fears and concerns in ASD (Hallett et al., 2013; Leyfer et al., 2006; Muris et al., 1999; Ozsivadjian et al., 2012; Trembath et al., 2012). Such non-typical symptoms and the overlapping of anxiety and ASD increase support for measures designed for this population, rather than adapting those for people of TD (Scahill, 2012).

The sensitivity and specificity of the Revised Children's Manifest Anxiety Scale (Reynolds \& Rishmond, 1978) and the Short Leyton Obsessional Inventory- Child Version (Bamber et al., 2002) were found lower in a community sample than previously reported vanSteensel et al. (2011) found lower levels of sensitivity and specificity for Dutch child and parent reference versions and validity was poorer for young people with ASD. Storch and colleagues (2012b) found that the PARS showed acceptable convergent validity (ICC correlation coefficient - 0.86) and correlation of re-coefficient ICC $=0.83$ when conducted after an interview provoking anxiety in a young person with ASD seeking treatment. Evidence was found of a separate structural factor for the MASC on parental reporting, but not for the children with or without ASD (White et al., 2014). Hallett and colleagues (2013) found DSM-4 to be consistent and to distinguish anxiety factors when tested with CASI-4 in young people with ASD in the UK. These findings support the idea that symptoms of anxiety may be manifested differently in young people with ASD, who may require a modified assessment approach, but they apply only to those seeking treatment.

Mattila and colleagues (2010), using the Kiddie Schedule for Affective Disorders and Schizophrenia with 50 children and their parents reported that the most common anxiety disorder in 9-16 years old children are phobia $(28 \%)$ and OCD $(22 \%)$.

Grondhuis \& Aman (2012) reviewed the variability (reported as $11 \%$ to $84 \%$ ) in the prevalence of anxiety disorders in children with ASD and highlighted the difficulties of anxiety measurement based on self-reports which may be limited by cognitive or verbal functions and questioned the relevance of the scale developed for non-ASD populations.

In a sample of 1.033 children with autism, Mayes and colleagues (2013) reported unusual fears, including fears of brooms, elevators, toys, swings and air in $41 \%$ of young people. Kerns et al. (2014) found a similar prevalence of standard anxiety symptoms (46\%), and non-standard anxiety symptoms in young people with ASD (148\%) using a short tool for assessing anxiety in young people with ASD (Kerns et al., 2015). Lecavallier et al. (2014) examined 10 such tools, concluding that only four are considered appropriate for use in clinical trials in children with ASD and under specific conditions related to their use. Some of the parameters that affect the difference between $11 \%$ and $84 \%$ in the various reports may be related to the child's age and the severity of the ASD.

The low cognitive function (IQ<70), of many children with ASD, estimated to be 38-50\% (Centers for Disease Control, 2012) may impede their ability to express anxiety. In their review Dawson and Bernier (2013) concluded that self-assessment instruments that are credible in children of TD may have limited utility in cognitively low functioning children with ASD. For this reason, parents and carers are often considered more reliable informants of the children's anxiety, bt even they find it difficult to infer which behaviors result from anxiety and which from ASD. In addition to verbal competence, the child's IQ may affect parental scoring, which tends to be higher for anxiety in children with higher IQ (Weisbrot et al., 2005; Hallett et al., 2013). In contrast, the meta-analysis of vanSteensel et al. (2011) documented higher rates of anxiety disorders in children with lower levels of mental 
function even if their anxiety is not expressed verbally.

Gender differences could not be addressed in some studies as few girls were involved but were explored, no differences were found (Kirkovski et al., 2013).

Some studies report more symptoms of anxiety in older than in younger children with ASD (Kuusikko et al., 2008; Lecavalier et al., 2006; Mayes et al., 2011; Vasa et al., 2014) while others noted no age (Farrugia \& Hudson, 2006; Hallett et al., 2013; Pearson et al., 2006; Sukhodolsky et al., 2008). The types of anxiety may be age related as a meta-analysis (vanSteensel et al., 2011) showed higher rates of that overall anxiety and GAD in older children and of separation anxiety and OCD in younger children with ASD.

Significant positive correlation between cognitive ability/adaptive function and increased symptoms of anxiety has been reported in ASD studies (Davis et al., 2008, Hallet et al., 2013b; Lecavalier, 2006; Mayes et al., 2011; Niditch et al., 2012) but not others (Brereton et al., 2006; Simonoff et al., 2008) and Kerns and Kendall (2012) suggested that cognitive abilities may be related to specific types of anxiety. Sukhodolsky and colleagues (2008) found that youngsters with IQ $>70$ were more likely to experience clinical symptoms, phobias, panic and social anxiety symptoms and severe general anxiety than those with IQ $<70$. Hallett and colleagues (2013b) also reported positive correlation of IQ with the parental score for social anxiety, but not panic or OCD symptoms.

Magiati and colleagues (2011) examined the association of age, adaptive function and severity of autistic symptoms with anxiety symptoms reported by the carers of $241,6-18$ year old children with ASD attending special schools in Singapore. The methods included SCAS and a global assessment of emotional, behavioral and adaptive functioning. More symptoms of overall anxiety but less social anxiety symptoms were detected by SCAS than in Australian samples. Differences in the overall anxiety score was best explained by the severity of the symptoms of repetitive verbal stereotypic behavior, which was an important predictor of separation anxiety, GAD, panic/ agoraphobia, and OCD, but not social phobia and fears of physical injury. Adaptive functionality and chronological age were related to social phobia and GAD. The degree of disability in social communication was not related to any anxiety symptom when the other factors were controlled for (Magiati et al., 2015).

\section{Discussion}

The configuration of the items scale requires caution when assessing the measurement of anxiety in ASD. In addition to being reliable and valid, the measurement should be sensitive to change over time and be able to distinguish between the most and the less commonly observed symptoms. An evaluation tool with a long list of items can be time-consuming and unfeasible for repeated measurements in long-range random tests. An ideal instrument should achieve a balance between absolute detection without tiring and confusing the individuals involved. If the evidence suggesting that panic disorder and PTSD are not common in children with ASD is confirmed by further studies, items related to these disturbances could be removed from a scale for children with ASD with no effect on the usefulness of the instrument. Special fears, social anxiety and separation anxiety are more common, and should be explored (White et al., 2009; vanSteensel et al., 2011; Kerns \& Kendall, 2012).

The expression of anxiety may be unique in children with ASD. The insistence of a child in following particular routines may be anxiety-driven and distress and over-reaction to change or to small frustrations may reflect the degree of anxiety. Instruments for use with children with AS should be able to detect such reactions. Even in children of TD, boundaries between anxiety disorders may not be clear, as children often have symptoms of more than one anxiety disorder (Walkup et al., 2008). Many young people with ASD face a variety of anxiety problems and may be overwhelmed by them (deBruin et al., 2007; Farrugia \& Hudson, 2006; Kerns et al., 2014; vanSteensel et al., 2011). The treatment of anxiety in ASD depends on accurate detection (Matson \& Nebel-Schwalm, 2007). Social avoidance, poor communication, repetitive and limited behaviors are common in ASD, but may resemble the traditional symptoms of anxiety (Cath et al., 208; Hartley \& Sikora, 2009). In addition, there is debate about whether anxiety occurs in a different way among children with ASD from those of TD (Ollendick \& White, 2012; Scahill, 2012; White et al., 2013; Wood \& Gadow, 2010).

Lack of consistency and stability in testing can make clinical treatment planning difficult because the clinicians may not be able to determine whether the levels of an anxiety disorder in a specific child with ASD are unusual. Clinical decisions on whether or not to treat anxiety comorbidity should be based on a variety for factors, for example, whether the level of anxiety interferes with day-to-day functioning or whether it appears in specific situations.

One issue raised by the studies is the sample selection and another is the procedure for collecting anxiety information on children with ASD. Usually the person competing the scale is the parents and the instrument, based on the DSM or a similar weighted scale, is completed in a interview. Concerning the source of information, 
however, there is evidence of differences between the anxiety rates reported by the parents of a child with an ASD and the self-reports given by the children themselves. Although some studies found that self-reporting anxiety scales in high-functioning young people with ASD are correlated with parent reports (Farrugia \& Hudson, 2006), others have reported that the parents' reports may have be more accurate (Russell \& Sofronoff, 2005). Parents usually record the anxiety of a child with ASD more severely than the child does (Blakeley, Smith et al., 2012; Russell \& Sofronoff, 2005), although others found that adolescents valuate their anxiety level higher than their parents; estimate (Storch et al., 2012a; Hurting et al., 2007). One study suggests that self-reports of children with ASD should be used with caution (Mazefsky et al., 2014), but another study using a biomaker in boys with ASD found that their self-evaluation, but not the parental assessment, was significantly related to the indication of the stress meter. White and colleagues (2009) investigated the relationships between anxiety, loneliness and social disability in a clinical sample of high functioning young people with ASD, using both the parents and children and adolescents as informants. The primary purpose was to explore self-reports on the experience of anxiety in young people with ASD. The hypotheses were that young people with more social disability would report more symptoms of anxiety.

Concerning the type of evaluation process used, some studies include data from a professional interview (Storch et al., 2012a) while others are based solely on self-reports and/or reports by parents and teachers. Some reviews (Matson \& Nebel-Schwalm, 2007; vanSteensel et al., 2011; White et al., 2009) have highlighted the problems of a categorical system of information collection (not enough symptoms to meet the required diagnostic criteria) rather than a method that determines the relative severity of anxiety disorder in a continuous or multi-scale (as used in some weighted questionnaires). As a result, the reviewers offer directions for further research on the impact of the evaluation process and sources. For example, White and colleagues (2009) reviewed 40 reports on this issue and suggested the inclusion of several sources of assessment (the parents and the children themselves) and different types of assessment methods (e.g., diagnostic scales based on the DSM-5 categorical system, and in addition weighted scales and the use of non-dichotomous percentages of symptoms) when measuring anxiety in a population with ASD. In a meta-analysis of 31 studies on anxiety in children with ASD, including a total of 2.121 participants under the age of 18 years, reported that "the studies were largely dominated by parents' reports". Achenbach and colleagues (1987) found only moderate levels of accordance between parents' assessment of child anxiety and children's self reporting of their anxiety, so it was not possible to "effectively trap" the true state of a child's anxiety from the child reports only. Another review, not specifically related to ASD, showed that parents tended to report more symptoms of dysfunction in their children when they were selected from a clinical rather than the general population (Montgomery, 2008). The overall conclusion is that, although people with ASD may have difficulty in describing internalized symptoms of anxiety due to communication deficits, social skills, and mental functioning and reliable diagnostic information is difficult to obtain self-reporting should be included in the assessment (Reiss, Levitan, \& Szyszko, 1982; Kerns, Renno, Kendall, Wood, \& Storch, 2017).

Two methodological issues arise concerning future research on the prevalence of anxiety disorders in children with ASD. Firstly, the use of multiple informants is recommended for future studies, particularly involving children with ASD as informants as they may be expected to have a more direct assessment of their own anxiety state. Secondly, different forms of anxiety assessment should be included in the protocols, in order to be compared with DSM- 5 based split rankings and percentage scales that allow a wider range of scores in diagnostic criteria, rather than simply examining whether symptoms are present or absent.

\subsection{Clinical Implications}

Concerning diagnostic evaluation, certain recommendations can be made. In the office, clinicians should conduct a physical and mental status examination when evaluating anxiety. Elevated heart rate or blood pressure may reflect situational anxiety related to the medical procedure or office visit. Other anxiety signs include tremors, nail biting, bald spots secondary to hair pulling, and skin lesions due to skin picking. A palpable thyroid, fine skin or hair pulling, and skin lesions due to skin picking. A palpable thyroid, fine skin or hair, and/or brisk tendon reflexes suggest checking the thyroid status as a possible cause of anxiety symptoms. Mental status examination may reveal poor eye contact, negative affect (e.g. fear, irritability), and changes in communication (e.g. stuttering, increased vocalizations, decreased verbal exchanges). The presence of disruptive behaviors may reflect anxiety or a desire to escape from the situation and therefore require careful assessment. Some children may not exhibit signs of anxiety on examination even though they experience anxiety in other settings (Sclauch, Gordon, Schmidt et al., 2007).

Assessment should be made for specific anxiety disorders and anxiety symptoms related to ASD. Many young people with ASD meet criteria for anxiety disorders according to (DSM-5) (Table 1) but they may exhibit atypical anxiety symptoms that do not fit, such as, anxiety about sensory stimuli, changes or social situations. The 
assessment of anxiety is children with ASD should therefore focus on both categorical and atypical symptoms (Baron, 2008). There is wide variation and, for example, some individuals are debilitated by change and others by social transactions (White \& Roberson-Nay, 2009; Spiker et al., 2011). There may be concomitant problems such as nervousness, aggression and hyperactivity (Lecavalier, 2006; White et al., 2009). Although the relationship of these problems with the defined features of the ASD is not entirely clear, they may complicate the clinical picture and contribute to the overall disability of the disorder (Lohr et al., 2017; Postorino et al., 2017).

Clinicians should inquire about the function of the ritualistic behaviors and ask questions to help to understand whether overlapping symptoms are explained solely by ASD or are consistent with a concomitant anxiety disorder. A referral to a behavioral psychologist, who can conduct a functional behavioral analysis, may help differentiate these etiology into the various forms of anxiety (Blakeley-Smith et al., 2012). It is important to distinguish preexisting ASD characteristics from new-onset anxiety symptoms and to recognize intensification of symptoms.

The clinician should also assess and treat other psychiatric and medical conditions that may cause or aggravate anxiety. Treating other conditions that may exacerbate anxiety should therefore be part of the treatment plan and should be considered before treating anxiety directly (Cath et al., 2008).

Comorbidity is prevalent in young people with ASD but may also reflect the presence of anxiety. For example, gastrointestinal and sleep may both cause and aggravate anxiety. Complex partial seizures may present with anxiety-like symptoms, including fear, misperceptions, and irritability. Some medications (e.g. psychostimulants, bronchodilators, allergy medications) can cause anxiety and may need to be changed.

Psychological stressors and suboptimal behavioral and educational supports may contributing to anxiety and need to be addressed. Many children with ASD have a strong need for "sameness" and prefer predictable routines and schedules. These changes may be minor (e.g. desks moved in class) or substantial (e.g. new school, loss of a one -to- one aide, loss of in-home behavioral support services, change in a parent's job schedule) (Cath et al., 2008).

Anxiety may also result from a mismatch between the child's needs and the types of supports in place in his/her daily life. Unrecognized learning problems and gross or fine motor, speech and language difficulties may aggravate anxiety. Many children with ASD experience bullying and peer victimization in school, which may lead to significant anxiety.

Stressors in the family environment must also be evaluated. Parents of youth with AS experience greater stress than parents of children with Down's syndrome and children of TD. Parental anxiety may contribute to anxiety in children, through modeling of anxious and overprotective parenting behaviors (Myles et al., 2001).

Inquiring about recent stressors and working with parents to alleviate these stressors is critical. Clinicians can help with educational advocacy (e.g. talking to school staff or writing letters indicating the need for increased services at school), suggesting strategies to stabilize the home environment (e.g. increasing structure and predictability), assessing resources (e.g. behavioral therapy, respite care), and medical treatments). The child's anxiety level should be reassessed to determine if symptoms have decreased after modifying these stressors.

Children with ASD may differ in their ability to self-report symptoms of anxiety due to age, verbal fluency, and cognitive ability. If the child appears to be capable, it is important to assess his/her ability to understand the experts emotions (e.g. "Do you know what I mean by nervous or scared?" Tell me a time when you were nervous") and provide developmentally appropriate explanation of these emotional terms when needed. Some children may respond better to forced choice responses (i.e. those requiring a "yes" or "no" response) than open-ended questions. Other children may be able to provide responses using visual analog scales rather than through verbal response. If emotional insight is compromised, results must be interpreted cautiously.

Clinicians must rely on accurate reporting of children's anxiety symptoms by parents and other caregivers, which may include avoidance and crying in response to specific stimuli or contexts, freezing behavior, fearful affect, clinginess and increased repetitive behaviors and/or vocalizations. Irritability, tantrums, disruptive behavior, aggression, worsening sleep problems, and self-injury may also suggest the presence of anxiety. Parents with an anxiety disorder may have enhanced perceptions of anxiety in their child. Sometimes, there may be disagreement between parent and child reports. It is therefore important for clinicians to collect collateral information from school staff and other caregivers in the form of narratives and behavior reports to supplement their findings (Weissman et al., 2006). There are few well-validated tools for assessing anxiety in youth with ASD, and as such, clinicians often depend on measures used in children of TD when assessing anxiety in ASD. Some scales such as the SCARED show comparable psychometric properties in young people with ASD and those of TD, whereas others, such as the MASC, show factor structures that differ between the two groups. Preliminary data on the SCAS indicate that it may serve as an effective anxiety-screening tool in ASD. Data from two systematic reviews 
indicate support for additional anxiety scales in children with ASD the RCADS, the CASI-4R, and the PARS, but with measurement limitations in all three, and some of these scales may not detect atypical fears.

In summary, data from instruments used for children of TD should be interpreted cautiously when applied to ASD. It is preferable to use multiple sources of information (e.g. parents and child) and also reliable and valid scales to evaluate psychiatric symptoms (White et al., 2009).

After collecting all the relevant information data, the clinician should assess whether anxiety-related impairment is present (e.g. How much does anxiety interfere with daily functioning? Is functioning impaired across multiple settings?). Assessing the contribution of anxiety symptoms (e.g. schoolwork avoidance or behavioral challenges at school and home) to the overall impairment and functioning of the child with ASD will help in the prioritization of treatment (Esbensen et al., 2003).

\section{Conclusions and Recommendations}

This study aimed to review criteria of anxiety, instruments and the process of assessment of anxiety symptoms in individuals with ASD. Among the factors that make it difficult to estimate anxiety in children with ASD is the overlap of symptoms. Diagnostic uncertainty. I may result in the clinical setting and internal and external disorders may not be diagnosed. This increases the risk of not providing adequate support to these children, possibly resulting in greater difficulty in their social interaction and their inability to adapt to the school environment.

Cross checking of the anxiety symptoms with different instruments and methods, including information from parents and teachers, systematic observation of children with ASD in their natural environment, suspicion about possible triggers or causes of manifestation of anxiety symptoms could contribute to a more objective estimation of anxiety disorders in ASD and the design of targeted intervention strategies.

In the research setting Developmentally Appropriate Multi-Informant and multi-method assessment of anxiety in ASD is recommended: Current evidence supports the use of multiple assessment modalities and informants, including data from clinical interviews and scales gathered from several informants (e.g. child, parent and teachers), along with behavioral observations were possible. Assessment of anxiety in this population can be more laborious than in young people of TD because of compromised language and cognitive functions in the child and the presence of complex conditions that overlap with anxiety. It is also important to evaluate the effect of child and family stressors. The instruments developed for the assessment of anxiety in adults and children of TD may not adequately detect anxiety in children with ASD.

\section{References}

Achenbach, T. M., \& Rescorla, L. A. (2001). Manual for the ASEBA School-Age Forms \& Profiles. Burlington, VT: University of Vermont, Research Center for Children, Youth, \& Families. Child Dev., 71(2), 447-56.

Achenbach, T. M., McConaughy, S. H., \& Howell, C. T. (1987). Child/adolescent behavioral and emotional problems: Implications of cross-informant Correlations for situational specificity. Psychological Bulletin, 101, 213-232. https://doi.org/10.1037/0033-2909.101.2.213

Amaral, D. G., Bauman, M. D., \& Schumann, C. M. (2003).The amygdala and autism: implications from non-human primate studies. Genes Brain Behav., 2(5),295-302.

American Psychiatric Association. (1994). Diagnostic and statistical manual of mental disorders (4th ed., text revision). Washington, DC: American Psychiatric Association.

American Psychiatric Association. (2013). Diagnostic and statistical manual of mental disorders (5th ed.). Arlington, VA: American Psychiatric Publishing.

Apter, A., Brown, S. L., Korn, M. L., \& van Praag, H. M. (1991). Psychiatric disorders of childhood: The role of serotonin. In S.-L. Brown, \& H. M. van Praag (editors), Clinical and Experimental Psychiatry Monograph: No 4 The Role of Serotonin in Psychiatric Disorders (pp. 215-238). Philadelphia, PA: Brunner/Mazel.

Asher, S. R., \& Wheeler, V. A. (1985). Children's loneliness: A comparison of rejected and neglected peer status. Journal of Consulting and Clinical Psychology, 53(4), 500-505. https://doi.org/10.1037/0022-006X.53.4.500

Attwood, T. (2005). Asperger's Syndrome Guide for Parents and Professionals. Kingsley Plc Ltd.

Bailey, N. M., \& Andrews, T. M. (2003). Diagnostic Criteria for Psychiatric Disorders for Use with Adults with Learning Disabilities/Mental Retardation (DC-LD) and the diagnosis of anxiety disorders: a review. Journal of Intellectual Disability Research, 47(s1), 50-61.

Balboni, G., Battagliese, G., \& Pedrabissi, L. T. (2000). The psychopathology inventory for mentally retarded adults: factor structure and comparisons between subjects with or without dual diagnosis. Res Dev Disabil., 
21(4), 311-21.

Bamber, D., Tamplin, A., Park, R., et al. (2002). Development of a Short Leyton Obsessional Inventory for children and adolescents. Journal of the American Academy of Child and Adolescent Psychiatry, 41, 1246-1252.

Baron-Cohen, S. (2008). Theories of the autistic mind. The Psychologist, 21, 112-116.

Bastiaansen, D., Koot, H. M., Ferdinand, R. F., \& Verhulst, F. C. (2004). Quality of life in children with psychiatric disorders: self-, parent, and clinician report. J Am. Acad. Child. Adolesc. Psychiatry, 43(2), 221-30. https://doi.org/10.1097/00004583-200402000-00019

Bauminger, N., \& Kasari, C. (2000). Loneliness and friendship in high-functioning children with autism. Child Dev., $71(2), 447-56$.

Bellini, S. (2006). The development of social anxiety in adolescents with autism spectrum disorders. Focus on Autism and Other Developmental Disabilities, 21,138-145.

Berument, S. K., Rutter, M., Lord, C., Pickles, A., \& Bailey, A. (1999). Autism screening questionnaire: Diagnostic validity. British Journal of Psychiatry, 175, 444-451.

Blakeley-Smith, A., Reaven, J., Ridge, K., \& Hepburn, S. (2012). Parent-child agreement of anxiety symptoms in youth with autism spectrum disorders. Research in Autism Spectrum Disorders, 6, 707-716. https://doi.org/10.1016;ras.2011.07.020

Bowirrat, A., Chen, T. J. H., Blum, K., Madigan, M., et al., (2010). Neuro-psychopharmacogenetics and Neurological Antecedents of Posttraumatic Stress Disorder: Unlocking the Mysteries of Resilience and Vulnerability. Curr Neuropharmacol., 8(4), 335-358. https://doi.org/10.2174/157015910793358123

Bradstreet, L. E., Juechter, J. I., Kamphaus, R. W., Kerns, C. M., \& Robins, D. L. (2017). Using the BASC-2 Parent Rating Scales to Screen for Autism Spectrum Disorder in Toddlers and Preschool-Aged Children. $J$ Abnorm. Child Psychol., 45(2), 359-370. https://doi.org/10.1007/s10802-016-0167-3

Brereton, A. V., Tonge, B. J., \& Einfeld, S. L. (2006). Psychopathology in children and adolescents with autism compared to young people with intellectual disability. Journal of Autism and Developmental Disorders, 36, 863-870. https://doi.org/10.1007/s10803-006-0125-y

Cath, D. C., Ran, N., Smit, J. H., van Balkom, A. J. L. M., \& Comijs, H. C. (2008). The relationship between pervasive developmental disorders, OCD and social anxiety disorder in adults: A preliminary case controlled study. Psychopathology, 41, 101-110.

Centers for Disease Control and Prevention. (2012). Prevalence of autism spectrum disorders-Autism and developmental disabilities monitoring network, 14 sites, United States. MMW Surveill Summ, 61(3), 1-19.

Charlot, L., Deutsch, C.K., Albert, A., Hunt, A., Connor, D. F., \& Mcllvane, W. J. Jr. (2008). Mood and Anxiety Symptoms in Psychiatric In patients with Autism Spectrum Disorder and Depression. Journal of Mental Health Research in Intellectual Disabilities, 1(4), 238-253. https://doi.org/10.1080/19315860802313947

Constantino, J. N., \& Gruber, C. P. (2005). Social responsiveness scale: Manual. Los Angeles, CA: Western Psychological Services.

Corsello, C., Hus, V., Pickles, A., Risi, S., Cook, E. H., Jr, \& Leventhal, B. L. (2007). Between a ROC and a hard place: decision making and making decisions about using the SCQ. J Child Psychol Psychiatry, 48, 932-40. https://doi.org/10.1111/j.1469-7610.2007.01762.x

Davis, N. O, \& Carter, A. S. (2008). Parenting stress in mothers and fathers of toddlers with autism spectrum disorders: associations with child characteristics. J. Autism Dev Disord., 38(7), 1278-91. https://doi.org/10.1007/s10803-007-0512-z

Dawson, G., \& Bernier, R. A. (2013). Quarter century of progress on the early detection and treatment of autism $\begin{array}{llll}\text { spectrum disorder. Developmental Psychopathology, 4, 1455-1472. } & \text { 4, }\end{array}$ https://doi.org/10.1017/S0954579413000710

de Bruin, E. I., Ferdinand, R. F., Meester, S., de Nijs, P. F., \& Verheij, F. (2007). High rates of psychiatric

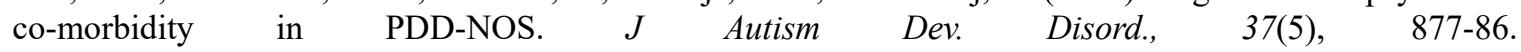
https://doi.org/10.1007/s10803-006-0215-x.

Dekker, M. C., Nunn, R., \& Koot, H. M. (2002). Psychometric properties of the revised Developmental Behaviour Checklist scales in Dutch children with intellectual disability. Journal of Intellectual Disability Research, 46(1), 61-75. https://doi.org/10.1046/j.1365-2788.2002.00353.x 
DeVincent, C. J., Gadow, K. D., Delosh, D., \& Geller, L. (2007). Sleep disturbance and its relation to DSM-IV psychiatric symptoms in preschool-age children with pervasive developmental disorder and community controls. Journal of Child Neurology, 22, 161-169. https://doi.org/10.1177/0883073807300310.

Esbensen, A. J., Rojahn, J., Aman, M. G., \& Ruedrich, S. (2003). Reliability and validity of an assessment instrument for anxiety, depression, and mood among individuals with mental retardation. J Autism Dev. Disord., 33(6), 617-29.

Evans, D. L., Charney, D. S., Lewis, L., Golden, R. N., Gorman, J. M., Krishnan, K. R., Nemeroff, C. B., ... \& Valvo, W. J. (2005). Mood disorders in the medically ill: scientific review and recommendations. Biol Psychiatry, 1, 58(3), 175-89. https://doi.org/10.1016/j.biopsych.2005.05.001

Farrugia, S., \& Hudson, J. (2006). Anxiety in adolescents with Asperger syndrome: Negative thoughts, behavioral problems, and life interference. Focus on Autism and Other Developmental Disabilities, 21(1), 25-35. https://doi.org/10.1177/10883576060210010401

Fischbach, G. D., \& Lord, C. (2010). The Simons Simplex Collection: A resource for identification of autism genetic risk factors. Neuron., 68(2),192-195. https://doi.org/10.1016/j.neuron.2010.10.006

Gadow, K. D., Devincent, C. J., Pomeroy, J., \& Azizian, A. (2005). Comparison of DSM-IV symptoms in elementary school-age children with PDD versus clinic and community samples. Autism, 9(4), 392-415. https://doi.org/ 10.1177/1362361305056079

Gillott, A., \& Standen, P. J. (2007). Levels of anxiety and sources of stress in adults with autism. $J$ Intellect Disabil., 11(4),359-70. https://doi.org/10.1177/1744629507083585

Glod, M., Creswell, C., Waite, P., Jamieson, R., McConachie, H., Don South, M., \& Rodgers, J. (2017). Comparisons of the Factor Structure and Measurement Invariance of the Spence Children's Anxiety Scale-Parent Version in Children with Autism Spectrum Disorder and Typically Developing Anxious Children. J. Autism Dev Disord., 47(12), 3834-3846. https://doi.org/10.1007/s10803-017-3118-0

Grondhuis, S. N., \& Aman, M. G. (2012). Assessment of anxiety in children and adolescents with autism spectrum disorders. Research in Autism Spectrum Disorders, 6, 1345-1365. https://doi.org/10.1016/j.rasd.2012.04.006

Hallett, V., Lecavalier, L., Sukhodolsky, D. G., Cipriano, N., Aman, M. G., McCracken, J. T., ... \& Scahill, L. (2013b). Exploring the manifestations of anxiety in children with Autism Spectrum Disorders. J Autism Dev. Disord., 43(10), 2341-2352. https://doi.org/10.1007/s10803-013-1775-1

Hallett, V., Ronald, A., Colvert, E., Ames, C., Woodhouse, E., Lietz, S., ... \& Happé, F. (2013). Exploring anxiety symptoms in a large-scale twin study of children with autism spectrum disorders, their co-twins and controls. J. Child Psychology and Psychiatry, 54(11), 1176-85.

Hartley, S. L, \& Sikora, D. M. (2009). Sex differences in autism spectrum disorder: an examination of developmental functioning, autistic symptoms, and coexisting behavior problems in toddlers. $J$ Autism Dev Disord., 39(12), 1715-22. https://doi.org/10.1007/s10803-009-0810-8

Hergüner, S., \& Motavalli, N. (2009). P02-105 Psychiatric comorbidity in children and adolescents with high functioning autism. European Psychiatry, 24(1) S 795. https://doi.org/10.1016/S0924-9338(09)71028-4

Herrington, J. D., Miller, J. S., Pandey, J., \& Schultz, R. T. (2016). Anxiety and social deficits have distinct relationships with amygdala function in autism spectrum disorder. Soc. Cogn. Affect Neurosci., 11(6),907-14. https://doi.org/10.1093/scan/nsw015

Hettema, J. M., Prescott, C. A., Myers, J. M., Neale, M. C., \& Kendler, K. S. (2005). The structure of genetic and environmental risk factors for anxiety disorders in men and women. Arch Gen Psychiatry, 62(2), 182-9. https://doi.org/10.1001/archpsyc.62.2.182

Hoehn-Saric, R., McLeod, D. R., \& Funderburk, F. (2004). Somatic Symptoms and Physiologic Responses in Generalized Anxiety Disorder and Panic Disorder An Ambulatory Monitor Study. Arch Gen Psychiatry, 61(9), 913921. https://doi.org/10.1001/archpsyc.61.9.913

Hurtig, T., Ebeling, H., Taanila, A., Miettunen, J., Smalley, S., McGough, J., et al. (2007). ADHD and comorbid disorders in relation to family environment and symptom severity. European Child and Adolescent Psychiatry, 16(6), 362-369. https://doi.org/10.1007/s00787-007-0607-2

James, A. L., \& Barry, R. J. (1984). Cardiovascular and electrodermal responses to simple stimuli in .autistic, retarded and normal children. International Journal of Psychophysiology, 1, 179-193. https://doi.org/10.1016/0167-8760(84)90037-0 
Jensen, P., Mrazek, D., Knapp, P., Steinberg, L., Pfeffer, C., Schowalter, J., \& Shapiro, T. (1997). Evolution and revolution in child psychiatry: ADHD as a disorder of adaptation. Journal of the American Academy of Child and Adolescent Psychiatry, 36, 1672-1679.

Keefer, A., Kreiser, N. L., Singh, V., Blakeley-Smith, A., Duncan, A., Johnson, C., ... \& Vasa, R. A. (2017). Intolerance of Uncertainty Predicts Anxiety Outcomes Following CBT in Youth with ASD. $J$ Autism Dev Disord., 47(12), 3949-3958. https://doi.org/10.1007/s10803-016-2852-z

Kerns, C. M., \& Kendall, P. C. (2012). Anxiety in autism spectrum disorders: Core or comorbid psychopathology? Clinical Psychology: Science and Practice, 12, 323-347.

Kerns, C. M, Kendall, P. C., Berry, L., Souders, M. C., Franklin, M. E., Schultz, R. T., Miller, J., \& Herrington, J. (2014). Traditional and atypical presentations of anxiety in youth with autism spectrum disorder. J. Autism Dev. Disorder, 44(11), 2851-61. https://doi.org/10.1007/s10803-014-2141-7

Kerns, C. M., Kendall, P. C., Zickgraf, H., Franklin, M. E., Miller, J., \& Herrington, J. (2015). Not to be overshadowed or overlooked: functional impairments associated with comorbid anxiety disorders in youth with ASD. Behavior therapy, 46, 29-39. https://doi.org/10.1016/j.beth.2014.03.005

Kerns, C. M., Maddox, B. B., Kendall, P. C., Rump, K., Berry, L., Schultz, R. T., .. \& Miller, J. (2015). Brief measures of anxiety in non-treatment-seeking youth with autism spectrum disorder. Autism, 19(8), 969-79. https://doi.org/10.1177/1362361314558465

Kerns, C. M., Renno, P., Kendall, P. C., Wood, J. J., \& Storch, E. A. (2017). Anxiety Disorders Interview Schedule-Autism Addendum: Reliability and Validity in Children With Autism Spectrum_Disorder. J. Clin Child Adolesc Psychol., 46(1), 88-100. https://doi.org/10.1080/15374416.2016.1233501.

Kessler, R. C., Demler, O., Frank, R. G., Olfson, M., Pincus, H. A., Walters, E. E., ... \& Zaslavsky, A. M. (2005). Prevalence and treatment of mental disorders, 1990 to 2003. $N$ Engl. J. Med., 16, 352(24), 2515-23. https://doi.org/10.1056/NEJMsa043266

Kim, J. A., Szatmari, P., Bryson, S. E., Streiner, D. L., \& Wilson, F. J. (2000). The prevalence of anxiety and mood problems among children with autism and Asperger syndrome. Autism, 4(2), 117-132. https://doi.org/10.1177/1362361300004002002

Kirkovski. M., Enticott, P. G., \& Fitzgerald, P. B. (2013). A review of the role of female gender in autism spectrum disorders. J. Autism Dev. Disord., 43(11), 2584-603. https://doi.org/10.1007/s10803-013-1811-1

Kleberg, J. L., Högström, J., Nord, M., Bölte, S., Serlachius, E., \& Falck-Ytter, T. (2016). Autistic Traits and Symptoms of Social Anxiety are Differentially Related to Attention to Others' Eyes in Social Anxiety Disorder. J Autism Dev. Disord., 47(12), 3814-3821. https://doi.org/10.1007/s10803-016-2978-z

Kristensen, H. (2000). Selective mutism and comorbidity with developmental disorder/delay, anxiety disorder and elimination disorder. J. Am, Acad Child Adolesc. Psychiatry, 39, 249-256.

Kuusikko, S., Pollock-Wurman, R., Jussila, K., Carter, A. S., Mattila, M. L., Ebeling, H., ... \& Moilanen, I. (2008). Social anxiety in high-functioning children and adolescents with Autism and Asperger syndrome. $J$ Autism Dev. Disord, 38(9), 1697-709. https://doi.org/10.1007/s10803-008-0555-9

LaBar, K. S., \& LeDoux, J. E. (2006). Fear and anxiety pathways. In: S. Moldin, \& J. L. Rubenstein (Eds.), Understanding Autism: From Basic Neuroscience to Treatment (pp. 133-154). Boca Raton, FL: CRC Press.

Lecavalier, L., Wood, J. J., Halladay, A. K., Jones, N. E., Aman, M. G., Cook, E. H., et al. (2014). Measuring anxiety as a treatment endpoint in youth with autism spectrum disorder. Journal of Autism and Developmental Disorders, 44(5), 1128-1143. https://doi.org/10.1007/s10803-013-1974-9

Lecavallier, L., Leone, S., \& Wiltz, J. (2006). The impact of behaviour problems on caregiver stress in young people with autism spectrum disorders. J. Intellect. Disabil Res.. 50(Pt 3), 172-83. https://doi.org/ 10.1111/j.1365-2788.2005.00732.x

Leyfer, O. T., Folstein, S. E., Bacalman, S., Davis, N. O., Dinh, E., Morgan, J., .. \& Lainhart, J.E. (2006). Comorbid psychiatric disorders in children with autism: interview development and rates of disorders. $J$ Autism Dev Disord,_36(7), 849-61. https://doi.org/10.1007/s10803-006-0123-0

Lohr, W. D., Daniels, K., Wiemken, T., Williams, P. G., Kelley, R. R., Kuravackel, G., \& Sears, L. (2017). The Screen for Child Anxiety-Related Emotional Disorders Is Sensitive but Not Specific in Identifying Anxiety in Children with High-Functioning Autism Spectrum Disorder: A Pilot Comparison to the Achenbach System of $\begin{array}{llllll}\text { Empirically Based Assessment Scales. Front Psychiatry, } & 2(8), & 138 .\end{array}$ 
https://doi.org/10.3389/fpsyt.2017.00138.eCollection2017

Lord, C., Rutter, M., DiLavore, P. C., \& Risi, S. (2002). Autism diagnostic observation schedule. Los Angeles: Western Psychological Services.

MacNeil, B. M., Lopes, V. A., \& Minnes, P. M. (2009). Anxiety in children and adolescents with autism spectrum disorders. Research in Autism Spectrum Disorders, 3(1), 1-21. https://doi.org/10.1016/j.rasd.2008.06.001.

Magiati, I. et al. (2011). Patterns of change in children with autism spectrum disorders who received community based comprehensive interventions in their pre-school years: A seven year follow-up study. Research in Autism Spectrum Disorders, 5(3), 1016-1027. https://doi.org/10.1016/j.rasd.2010.11.007

Magiati, I., Goh, D. A., Lim, S. J., Gan, D. Z. Q., Leong, J. C. L., Allison, C., ... \& Meaney M. J. (2015). The psychometric properties of the Quantitative-Checklist for Autism in Toddlers (Q-CHAT) as a measure of autistic traits in a community sample of Singaporean infants and toddlers. Mol Autism, 6, 40. https://doi.org/10.1186/s13229-015-0032-1

Masi, G., Brovedani, P., Mucci, M., \& Favilla, L. (2002). Assessment of anxiety and depression in adolescents with mental retardation. Child Psychiatry Hum Dev., 32(3), 227-37.

Matson, J. L., \& Love, S. R. (1990). A comparison of parent-reported fear for autistic and non-handicapped age-matched children and youth. Journal of Intellectual and Developmental Disability, 16(4), 349-357. https://doi.org/ 10.1080/07263869000034161

Matson, J. L., \& Nebel-Schwalm, M. S. (2007). Comorbid psychopathology with autism spectrum disorder in children: an overview. Res. Dev. Disabil., 28(4), 341-52. https://doi.org/10.1016/j.ridd.2005.12.004

Mattila, M. L., Hurtig, T., Haapsamo, H., Jussila, K., Kuusikko-Gauffin, S., Kielinen, M., ... \& Moilanen, I. (2010). Comorbid psychiatric disorders associated with Asperger syndrome/high-functioning autism: a community- and clinic-based study. $J$ Autism Dev Disord., 40(9), 1080-93. https://doi.org/10.1007/s10803-010-0958-2.

Mayes, S. D., Calhoun, S. L., Aggarwal, R., et al. (2013). Unusual fears in children with autism. Research in Autism Spectrum Disorders, 7, 151-158.

Mayes, S. D., Calhoun, S. L., Murray, M. J., Ahuja, M., \& Smith, L. A. (2011). Anxiety, depression, and irritability in children with autism relative to other neuropsychiatric disorders and typical development. Research in Autism Spectrum Disorders, 5(1), 474-485. https://doi.org/10.1016/j.rasd.2010.06.012

Mazefsky, C. A., Borue, X., Day, T. N., \& Minshew, N. J. (2014). Emotion Regulation Patterns in Adolescents With High-Functioning Autism Spectrum Disorder: Comparison to Typically Developing Adolescents and Association With Psychiatric Symptoms. Autism Res., 7(3), 344-354. https://doi.org/10.1002/aur.1366

McDougle, C. J., Kresch, L. E., Goodman, W. K., Naylor, S. T., Volkmar, F. R., Cohen, D. J., \& Price, L. H. (1995). A case-controlled study of repetitive thoughts and behavior in adults with autistic disorder and obsessive-compulsive disorder. Am. J. Psychiatry, 152(5), 772-7. https://doi.org/10.1176/ajp.152.5.772

Mehtar, M. M., \& Motavalli, N. (2011). Posttraumatic Stress Disorder in Individuals with Diagnosis of Autistic Spectrum Disorders. Research in Autism Spectrum Disorders, 5(1), 539-546.

Meiser-Stedman, R., McKinnon, A., Dixon, C., Boyle, A., Smith, P., \& Dalgleish, T. (2017). Acute stress disorder and the transition to posttraumatic stress disorder in children and adolescents: Prevalence, course, prognosis, diagnostic suitability, and risk markers. Depress Anxiety, 34(4), 348-355. https://doi.org/10.1002/da.22602

Mindham, J., \& Espie, C. A. (2003). Glasgow Anxiety Scale for People With Intellectual Disability (GAS-ID): Development and psychometric properties of a new measure for use with people who have mild intellectual $\begin{array}{llll}\text { disability. Journal of Intellectual Disability Research, 47, 22-30. } & \text {. }\end{array}$ https://doi.org/10.1046/j.1365-2788.2003.00457.x

Mitelman, S.A., Bralet, M.C., Mehmet, Haznedar. M., Hollander, E., Shihabuddin, L., Hazlett, E. A., \& Buchsbaum, M. S. (2017). Positron emission tomography assessment of cerebral glucose metabolic rates in autism spectrum disorder and schizophrenia. Brain Imaging Behav., 19. https://doi.org/10.1007/s11682-017-9721-z

Mohr, C., \& Costello, H. (2007) Mental health and monitoring tools for people with intellectual disabilities in N. Bouras \& G. Holt (Eds.), Psychiatric and Behavioral Disorders in Intellectual and Developmental Disabilities. Cambridge: Cambridge University Press.

Montgomery, J. M., Newton, B., \& Smith, C. (2008). Review of GARS-2: Gilliam Autism Rating Scale-Second 
Edition. [Review of the software GARS-2: Gilliam Autism Rating Scale-Second Edition. J. Gilliam]. Journal of Psychoeducational Assessment, 26(4), 395-401. https://doi.org/10.1177/0734282908317116.

Muris, P., Merckelbach, H., Wessel, I., \& Ven, M. (1999). Psychopathological correlates of self-reported behavioral inhibition in normal children. Behaviour Research and Therapy, 37, 575-584. https://doi.org/10.1016/S0005-7967(98)00155-7.

Myles, B., Barnhill, G., Hagiwara, T., Griswold, D., \& Simpson, R. (2001). A synthesis of studies on the intellectual, academic, social/emotional and sensory characteristics of children with asperger syndrome. Education and Training in Mental Retardation and Developmental Disabilities, 36, 304-311.

National Institute of Mental Health. (999b). Archival record-early recognition and treatment of schizophrenia and bipolar disorder in children and adolescents. Retrieved July 17, 2016, from http://www.nimh.nih.gov /events/earlyrecognition.cfm

Nauta, M. H., Scholing, A., Rapee, R. M., Abbott, M., Spence, S. H., \& Waters, A. (2004). A parent-report measure of children's anxiety: Psychometric properties and comparison with children port in a clinic and normal sample. Behaviour Research and Therapy, 42(7), 813-839. https://doi.org/10.1016/S0005-7967(03)00200-6.

Nidtich, A. L., Varela, R. E., Kamps, J. L., Hill, T. et al. (2012). Exploring the Association Between Cognitive Functioning and Anxiety in Children With Autism Spectrum Disorders: The Role of Social Understanding and Aggression. Journal of Clinical Child \& Adolescent Psychology, 41(2), 127-37. https://doi.org/10.1080/15374416.2012.651994

Ollendick, T. H., \& White, S. N. (2012). The presentation and classification of anxiety in autism spectrum disorder. Where to from here? Clinical Psychology Science and Practice, 19(4), 352-355. https://doi.org/10:1111;esp12013

Ozsivadjian, A., Knott, F., \& Magiati, I. (2012). Parent and child perspectives on the nature of anxiety in children and young people with autism spectrum disorders: A focus group study. Autism : The International Journal of Research and Practice, 16, 107-121. https://doi.org/ 10.1177/1362361311431703

Palkovitz, R. J., \& Wiesenfeld, A. R. (1980). Differential autonomic responses of autistic and normal children. $J$ Autism Dev. Disord., 10(3), 347-60.

Papadatos, J. (2010). Psychological Disorders and Learning Difficulties of Children and Adolescents. Athens: Gutenberg Plc.

Pearson, D. A., Loveland, K. A., Lachar, D., Lane, D. M., Reddoch, S. L., Mansour, R., et al. (2006). A comparison of behavioral and emotional functioning in children and adolescents with autistic disorder and PDD-NOS. Child Neuropsychology, 12, 321-333.

Piven, J., \& Palmer, P. (1999). Psychiatric disorder and the broad autism phenotype: Evidence from a family study of multiple-incidence autism families. American Journal of Psychiatry, 156, 557-563. https://doi.org/10.1176/ajp.156.4.557.

Polychronopoulou, S. (2012). Children and Adolescents with Special needs and Possibilities. Athens.

Postorino, V., Kerns, C. M., Vivanti, G., Bradshaw, J., Siracusano, M., \& Mazzone, L. (2017). Anxiety Disorders and Obsessive-Compulsive Disorder in Individuals with Autism Spectrum Disorder. Curr. Psychiatry Rep., 30, 19(12), 92. https://doi.org/10.1007/s11920-017-0846-y

Ramirez, S. Z, \& Lukenbill, J. F. (2007). Development of the fear survey for adults with mental retardation. Res. Dev. Disabil., 28(3), 225-37. https://doi.org/10.1016/j.ridd.2006.01.001

Reiss, S., Levitan, G. W., \& Szyszko, J. (1982). Emotional disturbance and mental retardation: diagnostic overshadowing. Am. J Ment. Defic., 86(6), 567-74.

Renno, P., \& Wood, J. J. (2013). Discriminant and convergent validity of the anxiety construct in children with autism spectrum disorders. $J$ Autism Dev. Disord., 43(9), 2135-46. https://doi.org/10.1007/s10803-013-1767-1

Reynolds, C. R., \& Kamphaus, R.W. (2004). Behavior Assessment System for Children (2nd ed.). Circle Pines, MN: American Guidance Service.

Reynolds, C. R., \& Richmond, B. O. (1978). What I think and feel: A revised measure of children's manifest anxiety. Journal of Abnormal Child Psychology, 6(2), 271-280. https://doi.org/10.1007/BF00919131

Romanczyk, R. G., Gills, J. M., Baron, M. G., et al., (2006). Autism and the Psychology of Stress and Anxiety. Stress and coping in Autism. New York. NY: Oxford University Press. 
Ronan, K. R., Kendall, P. C., \& Rowe, M. (1994). Negative affectivity in children: development and validation of a self-statement questionnaire. Cognitive Therapy and Research, 18, 509-528. https://doi.org/10.1007/BF02355666.

Rowney, J., Hermida, T., \& Malone. D. (2010). Anxiety Disorders. Current Clinical Medicine, 944-948.

Rumsey, J. M., Rapoport, J. L., \& Sceery, W. R. (1985). Autistic children as adults: Psychiatric, social, and behavioral outcomes. Journal of the American Academy of Child Psychiatry, 24, 465-473. https://doi.org/10.1016/S0002-7138(09)60566-5

Russell, E., \& Sofronoff, K. (2005). Anxiety and social worries in children with Asperger syndrome. Australian and New Zealand Journal of Psychiatry, 39, (7), 633-638. https://doi.org/10.1080/j.1440-1614.2005.01637.x

Rutter, M., Le Couteur, A., \& Lord, C. (2003). Autism Diagnostic Interview-Revised (ADI-R) manual. Los Angeles: Western Psychological Services.

Rydell, A.M., Hagekull, B., \& Bohlin, G. (1998). Measurement of two social competence aspects in middle childhood: Correction to Rydell et al. (1997). Developmental Psychology, 34(1), 2. https://doi.org/10.1037/h0092675.

Scahill, L., McDougle, C. J., Aman, M. G., Johnson, C., Handen, B., Bearss, K., ... \& Research Units on Pediatric Psychopharmacology Autism Network. (2012). Effects of risperidone and parent training on adaptive functioning in children with pervasive developmental disorders and serious behavioral problems. J. Am. Acad. Child Adolesc. Psychiatry, 51(2), 136-46. https://doi.org/10.1016/j.jaac.2011.11.010

Schopler, E., \& Mesibov, G. B. (Eds.) (1994). Behavioral issues in autism. New York: Plenum.

Sclauch, R. C., Gordon, K. H., Schmidt, N. B. et al. (2007). The assessment diagnosis and treatment of psychiatric disorders in individuals with a dual diagnosis. The co-occurrence on developmental disorders and psychiatric disorders. In Buckner, J. D., Castro, Y., Holm Denoma, J. M., \& Joiner, T. F. (Eds., pp. 101-121), Mental Health Care for People of Diverse Backgrounds. Abingdon: UK Radcliffe, Publishing 2007.

Simonoff, E., Pickles, A., Charman, T., Chandler, S., Loucas, T., \& Baird, G. (2008). Psychiatric disorders in children with autism spectrum disorders: Prevalence, comorbidity, and associated factors in a population-derived sample. Journal of the American Academy of Child and Adolescent Psychiatry, 47(8), 921. https://doi.org/10.1097/CHI.0b013e318179964f

Spiker, M., Enjey, L. C., Van Dyke, M., Wood, J. J. et al. (2011). Restricted interests and anxiety in children with autism. Autism, 16(3), 306-20. https://doi.org/10.1177/1362361311401763.

Stavrakaki, C., \& Lunsky, Y. (2007). Depression, anxiety and adjustment disorders in people with intellectual disabilities, in N. Bouras \& G. Holt (Eds.), Psychiatric and behavioral disorders in intellectual and developmental disabilities (2nd ed., pp. 113-130). Cambridge: Cambridge University Press.

Stein, M. B., Sherbourne, C. D, Craske, M. G., Means-Christensen, A., Bystritsky, A., Katon, W., ... Roy-Byrne, P. P. (2004). Quality of care for primary care patients with anxiety disorders. Am. J Psychiatry, 161(12), 2230-7. https://doi.org/10.1176/appi.ajp.161.12.2230

Stevens, S., \& Gruzelier, J. (1984). Electrodermal activity to auditory stimuli in autistic, retarded, and normal children. J Autism Dev. Disord., 14(3), 245-60.

Storch, E. A., Wood, J. J., Ehrenreich, M. J., Lewin, A. B., Jones, A. M., Park, J. M., \& Murphy, T. K. (2012a). Convergent and divergent validity and reliability of the Pediatric Anxiety Rating Scale. Journal of Autism and Developmental Disorders, 42, 2374-2382. https://doi.org/10.1007/s10803-012-1489-9

Sukhodolsky, D. G., Scahill, L., Gadow, K. D., Arnold, L. E., Aman, M. G., McDougle, C. J., et al. (2008). Parent-rated anxiety symptoms in children with pervasive developmental disorders: Frequency and association with core autism symptoms and cognitive functioning. Journal of Abnormal Child Psychology, 36(1), 117. https://doi.org/10.1007/s10802-007-9165-9

Telman, L. G. E., van Steensel, F. J. A., Maric, M., \& Bögels, S. M. (2017). Are Anxiety Disorders in Children and Adolescents Less Impairing Than ADHD and Autism Spectrum Disorders? Associations with Child Quality of Life and Parental Stress and Psychopathology. Child Psychiatry Hum. Dev., 48(6), 891-902. https://doi.org/10.1007/s10578-017-0712-5

Trembath, D. et al. (2012). The Experience of Anxiety in Young Adults With Autism Spectrum Disorders December. Focus on Autism and Other Developmental Disabilities, 27(4), 213-224. https://doi.org/10.1177/1088357612454916 
van Steensel, F. J. A., Bogels, S. M., \& Perrin, S. (2011). Anxiety disorders in children and adolescents with autistic spectrum disorders: A meta-analysis. Clinical Child and Family Psychology Review, 14(3), 302-317. https://doi.org/10.1007/s10567-011-0097-0

Vasa, R. A., Carroll, L. M., Nozzolillo, A. A., Mahajan, R., Mazurek, M. O., Bennett, A. E., Wink L. K., \& Bernal, M. P. (2014). A systematic review of treatments for anxiety in youth with autism spectrum disorders. $J$ Autism Dev. Disord., 44(12), 3215-29. https://doi.org/10.1007/s10803-014-2184-9

Vasa, R. A., Mazurek, M. O., Mahajan, R., Bennett, A. E., Bernal, M. P., Nozzolillo, A. A., ... \& Coury, D. L. (2016). Assessment and Treatment of Anxiety in Youth With Autism Spectrum Disorders. Pediatrics, 137(S2), e20152851J. https://doi.org/10.1542/peds.2015-2851J

Walkup, J. T., Albano, A. M., Piacentini, J., Birmaher, B., Compton, S. N., Sherrill, J. T., ... \& Kendall, P. C. (2008). Cognitive behavioral therapy, sertraline, or a combination in childhood anxiety. N. Engl. J Med., 25,359(26), 2753-66. https://doi.org/10.1056/NEJMoa0804633

Weisbrot, D. M., Gadow, K. D., DeVincent, C. J., \& Pomeroy, J. (2005). The presentation of anxiety in children with pervasive developmental disorders. $J$ Child Adolesc. Psychopharmacol., 15(3), 477-96. https://doi.org/10.1089/cap.2005.15.477

Weissman, M. M., Wickramaratne, P., Nomura, Y., Warner, V., Pilowsky, D., \& Verdeli, H. (2006). Offspring of depressed parents: 20 years later. Am. J Psychiatry, 163(6), 1001-8. https://doi.org/10.1176/ajp.2006.163.6.1001

White, S. W., \& Roberson-Nay, R. (2009). Anxiety, social deficits, and loneliness in youth with autism spectrum disorders. Journal of Autism and Developmental Disorders, 39, 1006-1013. https://doi.org/10.1007/s10803-009-0713-8

White, S. W., Lerner, M. D., McLeod, B. D., et al. (2014). Anxiety in youth with and without autism spectrum disorder: examination of factorial equivalence. Behavior Therapy. https://doi.org/10.1016/j. beth.2014.05.005

White, S. W., Maddox, B. B., \& Panneton, R. K. (2015). Fear of negative evaluation influences eye gaze in adolescents with autism spectrum disorder: A pilot study. Journal of Autism and Developmental Disorders, 45, 3446-3457. https://doi.org/10.1007/s10803-014-2349-6

White, S. W., Oswald, D., Ollendick, T., \& Scahill, L. (2009). Anxiety in children and adolescents with autism spectrum disorders. Clinical Psychology Review, 29(3), 216-229. https://doi.org/10.1016/j.cpr.2009.01.003.

Wigham, S., \& McConachie, H. (2014). Systematic Review of the Properties of Tools Used to Measure Outcomes in Anxiety Intervention Studies for Children with Autism Spectrum Disorders Published, 21. PLOS. https://doi.org/10.1371/journal.pone.0085268 .

Wood, J. J., \& Gadow, K. D. (2010). Exploring the nature and function of anxiety in youth with autism spectrum disorders. Clinical Psychology: Research and Practice, 17, 281-292. https://doi.org/10.1111/j.1468-2850.2010.01220.x

Wozniak, J., Biederman, J., Mundy, E., Mennin, D., \& Faraone, S. V. (1995). A pilot family study of childhood-onset mania. $J$ Am. Acad. Child Adolesc Psychiatry, 34(12), 1577-1583. https://doi.org/10.1097/00004583-199512000-00007

Zahn, T. P., Rumsey, J. M., \& Van Kammen, D. P. (1987). Autonomic nervous system activity in autistic, schizophrenic, and normal men: effects of stimulus significance. J Abnorm. Psychol., 96(2), 135-44. https://doi.org/10.1037/0021-843X.96.2.135

\section{Copyrights}

Copyright for this article is retained by the author(s), with first publication rights granted to the journal.

This is an open-access article distributed under the terms and conditions of the Creative Commons Attribution license (http://creativecommons.org/licenses/by/4.0/). 